\title{
Capsaicin enhances the non-adrenergic twitch response of rat vas deferens
}

\author{
Hideki Moritoki, Takeshi Iwamoto, Jun Kanaya, Yukio Ishida, *Kenshi Ando \& \\ *Kouki Kitagawa
}

Department of Chemical Pharmacology, *Department of Chemical \& Pharmaceutical Technology, Faculty of Pharmaceutical Sciences, University of Tokushima, Shomachi, Tokushima 770, Japan

1 Capsaicin (Cap) enhanced the twitch response of the epididymal and prostatic portions of rat vas deferens induced by field stimulation at $0.1 \mathrm{~Hz}$. The effect of Cap was reproducible and showed no desensitization.

2 Prazosin, and pretreatment with reserpine or Cap did not affect the potentiating effect of Cap, whereas pretreatment with 6-hydroxydopamine abolished the action of Cap.

3 Cap tended to attenuate the contractions induced by noradrenaline, tyramine and ATP.

4 Like Cap, substance $K$ and substance $P$ augmented the twitch response without causing desensitization, but their effects differed somewhat from that of Cap. Calcitonin gene-related peptide inhibited the twitch response.

5 These results suggest that Cap enhances a stimulation-induced, prazosin-resistant non-adrenergic twitch response of rat vas deferens through an as yet undefined prejunctional mechanism. This mechanism is possibly mediated by some peptide released in response to Cap from sensory neurones, which in turn acts on sympathetic nerves and increases stimulation-induced release of a mediator or cotransmitter responsible for the non-adrenergic twitch response. However, the possibility that Cap has a direct action on sympathetic nerves cannot be ruled out.

\section{Introduction}

Capsaicin (Cap), the pungent ingredient of hot peppers, is known to deplete primary sensory neurones of substance P (SP) (Jessell et al., 1978; Gamse et al., 1979), and has been used in studies on the possible role of SP as a mediator in several biological responses. Acute release or depletion of SP from both central peripheral neurones seems to be responsible for several Cap-induced responses. There is evidence that Cap causes neuronally mediated contractions of guinea-pig ileum by releasing SP (Barthó et al., 1982; Chahl, 1982). In guinea-pig taenia coli, Cap releases an unknown mediator from sensory neurones, which in turn stimulates cholinergic nerves of the myenteric plexus (Szolcsányi \& Barthó, 1979). The Cap-induced contractions of guinea-pig trachea (Szolcsányi \& Barthó, 1982) and ureter (Hua \& Lundberg, 1986), rat urinary bladder (Maggi et al., 1985; Santicioli et al., 1986) and rabbit sphincter pupillae (Wahlestedt $e t$ al., 1985 ) and the Cap-induced positive inotropic response of guinea-pig atria (Lundberg et al., 1984) have been assumed to be mediated by some peptides released from sensory nerve endings. In addition to these stimulatory effects, Cap is also reported to inhibit the motility of rat ureter by releasing a neuropeptide from sensory nerve endings (Maggi et al., 1986c) and to cause relaxation of rat duodenum by activating an intramural inhibitory non-adrenergic, non-cholinergic mechanism (Maggi et al., 1986a,b). An involvement of Cap-sensitive sensory neurones in the vasodilator response has also been reported (Duckles \& Buck, 1982; Rózsa et al., 1984; 1985). However, there is no report on the effect of Cap on the response induced by nerve stimulation.

In this work we examined the effect of Cap on the non-adrenergic twitch response of rat vas deferens induced by field stimulation and the possibility that a Cap-sensitive mechanism is involved in regulation of this motor response.

\section{Methods}

Wistar rats of 8 to 10 weeks of age were lightly anaesthetized with diethyl ether, killed by a blow to the head, and cervical dislocation and bled. Vasa deferentia were separated from connective tissue under a 
dissecting microscope, and cut into epididymal and prostatic portions constituting $50 \%$ and $40 \%$, respectively, of the total length. Each preparation was set up in $10 \mathrm{ml}$ organ bath containing Krebs solution of the following composition (mM): $\mathrm{NaCl} 115.3, \mathrm{KCl} \mathrm{4.7}$, $\mathrm{CaCl}_{2}$ 1.6, $\mathrm{MgSO}_{4} 1.2, \mathrm{NaHCO}_{3} 25.0, \mathrm{KH}_{2} \mathrm{PO}_{4} 1.2$ and glucose 11.1. The medium was maintained at $35^{\circ} \mathrm{C}$ and bubbled with $5 \% \mathrm{CO}_{2}$ in $\mathrm{O}_{2}$. The resting tension of the preparation was maintained at $200 \mathrm{mg}$, and after an equilibration period of $60 \mathrm{~min}$, field stimulation of $0.5 \mathrm{~ms}$ duration was applied at a frequency of $0.1 \mathrm{~Hz}$ or $2 \mathrm{~Hz}$ from a stimulator (Nihon Kohoden SEN 3201) with a constant voltage modulator through a pair of platinum electrodes. One electrode was placed around the preparation, and the other was attached to one end of the preparation. Contractions were recorded isometrically with a force displacement transducer (Nihon Kohoden SD 1TH). The twitch contractions elicited by field stimulation were abolished by either tetrodotoxin $(0.1 \mu \mathrm{M})$ or guanethidine $(3 \mu \mathrm{M})$, indicating that the response was neurogenic.

For construction of a dose-response curve, capsaicin (Cap) was added cumulatively in a volume of 10 to $70 \mu \mathrm{l}$ to the $10 \mathrm{ml}$ organ bath. Other compounds were applied $10 \mathrm{~min}$ before $\mathrm{Cap}$, unless otherwise stated. In tests on the effects of Cap on the contractions induced by noradrenaline (NA), tyramine and ATP, Cap was added 10 min before these agents. A stock solution of $100 \mathrm{mM}$ Cap in ethanol was prepared, and this solution was diluted with saline immediately before use.

For depletion of NA, rats were treated with reserpine $4 \mathrm{mg} \mathrm{kg}^{-1}$ (s.c.) on day 1 and $2 \mathrm{mg} \mathrm{kg}^{-1}$ on day 2 , and killed on day $3,2 \mathrm{~h}$ after the last injection of reserpine. For denervation of sympathetic nerves, animals were treated with 6-hydroxydopamine (6OHDA) at doses of $250 \mathrm{mg} \mathrm{kg}^{-1}$ (i.p.) on day 1 and $200 \mathrm{mg} \mathrm{kg}^{-1}$ on day 3 and killed on day 4 . The absence of tyramine-induced contractions of the preparation was checked to confirm that reserpine and 6-OHDA has been effective.

Some rats were treated with Cap at doses $100 \mathrm{mg} \mathrm{kg}^{-1}$ on day 1 and $150 \mathrm{mg} \mathrm{kg}^{-1}$ on day 3 and killed on day 5. Failure of Cap to induce relaxation of the duodenum was taken as an indication that this pretreatment had been effective.

All results are given as means \pm s.e.mean. Student's $t$ test was used to determine the significance of differences between values for control and treated preparations, and $P$ values of less than 0.05 were considered to be significant.

The drugs used were capsaicin (Sigma Chemical Co. Ltd, St Louis, Mo), calcitonin gene-related peptide ( $\alpha$ rat CGRP, synthesized by Ando et al., 1987), substance P (Peptide Institute, Osaka, Japan), substance $\mathbf{K}$ (neurokinin A, synthesized in this laboratory), prazosin (Taito-Pfeizer, Tokyo, Japan), yohimbine hydrochloride (Sigma), reserpine (Sigma), 6-hydroxydopamine hydrobromide (Nakarai Chemicals Ltd, Kyoto, Japan), noradrenaline bitartrate (Wako Pure Chemical Ind. Ltd, Osaka, Japan), tyramine hydrochloride (Nakarai), ATP (Sigma), cimetidine (Smith Kline \& French Lab., Philadelphia, PA), chlorpheniramine maleate (Sigma), indomethacin (Sigma), nordihydroguaiaretic acid (Sigma), cocaine hydrochloride (Takeda Pharmaceutical Co. Ltd, Osaka, Japan), desipramine hydrochloride (Fujisawa Pharmaceutical Co. Ltd, Osaka, Japan), ketanserin (Janssen Pharmaceutica, Beerse, Belgium) and methylene blue (Sigma).

\section{Results}

\section{Potentiating effect of capsaicin on the twitch response}

When added cumulatively, capsaicin (Cap) at concentrations of above $10 \mu \mathrm{M}$ caused dose-dependent augmentation of the twitch response of rat whole vas deferens induced by field stimulation at $0.1 \mathrm{~Hz}$ (Figure 1). The maximal potentiation of $262.6 \pm 57.7 \%(n=6)$ was achieved with $60 \mu \mathrm{M}$ Cap, and the apparent $\mathrm{pD}_{2}$ value was $4.55 \pm 0.05$. Conversely, at above $200 \mu \mathrm{M}$, Cap attenuated the augmented response. As shown in Figure 1b, after a single dose of Cap $(300 \mu \mathrm{M})$, the twitch response promptly increased but then gradually decayed. On the other hand, the potentiation by a single dose of Cap at a low concentration $(60 \mu \mathrm{M})$ was sustained without fading, and was greater than that caused by $300 \mu \mathrm{M}$ Cap. Both the potentiating effect of Cap at lower concentrations and its dual effects (initial potentiation and following attenuation and/or inhibition) at higher concentrations were reproducible.

Next, we examined the effect of Cap on the different portions of the vas deferens, the epididymal and prostatic portions. In the prostatic portion, Cap augmented the twitch response with $\mathrm{pD}_{2}$ value of $4.62 \pm 0.06(n=7)$ and the relative potentiation $(311.1 \pm 60.7 \%, n=8)$ was greater than that in the epididymal portion $(241.6 \pm 76.2 \%, n=8)$.

The potentiating effect of Cap was not substantially different in various experimental conditions, such as with different calcium concentrations (1.0-4.0 mM), pulse durations $(0.3-2.0 \mathrm{~ms})$, types of electrode (two ring, parallel, coaxial) and intervals between single pulses (data not shown).

Next, we examined the effects of Cap in preparations from young and old rats. As shown in Table 1, Cap enhanced the response of preparations from rats of all ages tested, although the relative potentiation was greater in preparations with a low initial twitch tension (3-4 weeks old) than in those with a higher tension (8 weeks old). 


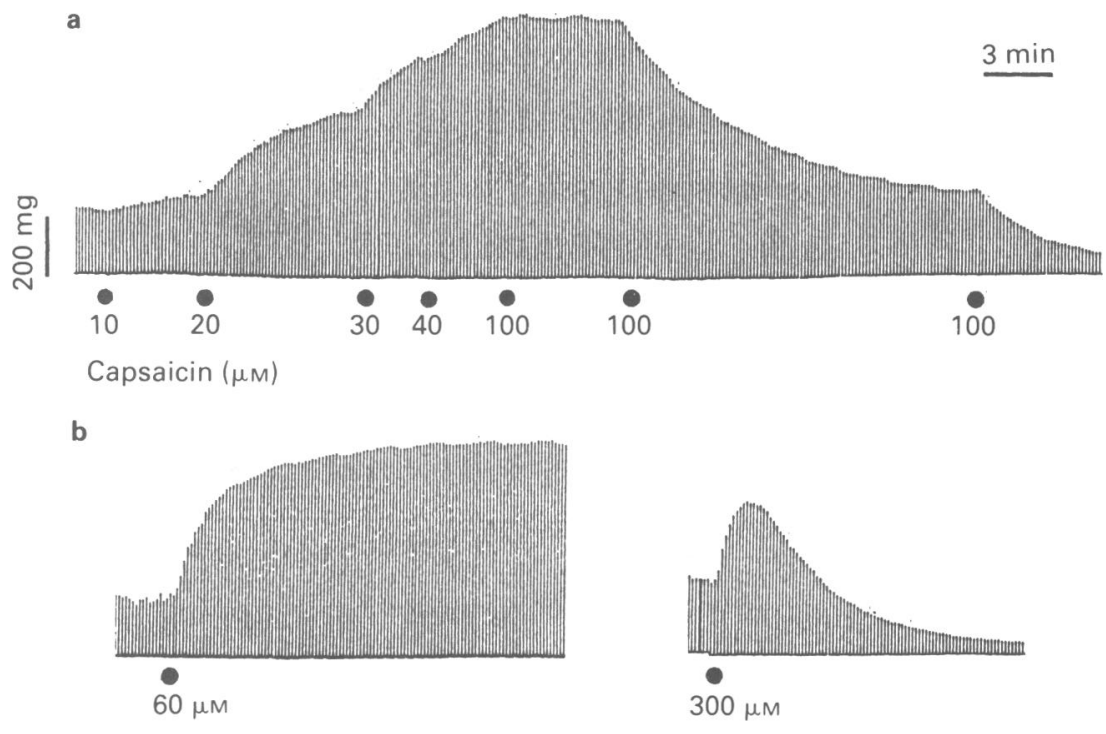

Figure 1 Typical records showing the potentiating effect of capsaicin on the twitch response of rat whole vas deferens induced by a single pulse field stimulation at $0.1 \mathrm{~Hz}$ : (a) shows the effect of capsaicin added cumulatively, and (b) shows the effect of its addition in a single dose. Capsaicin was added at the times indicated by dots.

Cap alone at concentrations of 10 to $200 \mu \mathrm{M}$ did not induce contractions of the vas deferens, but at a concentration of $30 \mu \mathrm{M}$, it inhibited the contractions of the epididymal portion to $0.1 \mu \mathrm{M}$ NA by $29.0 \pm 8.8 \%$ $(n=4)$ and to $10 \mu \mathrm{M}$ tyramine by $23.5 \pm 15.9 \%$ $(n=4)$, and the contractions of the prostatic portion to $100 \mu \mathrm{M}$ ATP by $43.3 \pm 8.5 \%(n=5)$. At a higher concentration of $200 \mu \mathrm{M}$ Cap, it completely abolished these NA-, tyramine- and ATP-induced contractions.

\section{Effects of reserpine, 6-hydroxydopamine, and other inhibitors}

Reserpine After treatment with reserpine, the epididymal portion of the vas deferens no longer

Table 1 Potentiating effect of capsaicin on the whole vas deferens from rats of different ages.

\begin{tabular}{lcccc}
\hline $\begin{array}{l}\text { Age } \\
\text { (weeks) }\end{array}$ & $\begin{array}{c}\text { Initial } \\
\text { tension } \\
(\mathrm{mg})\end{array}$ & $\begin{array}{c}\text { Relative } \\
\text { potentiation } \\
(\% \text { initial) }\end{array}$ & $\begin{array}{c}\text { Apparent } \\
p D_{2} \text { value }\end{array}$ & $\mathrm{n}$ \\
$3-4$ & $31.8 \pm 13.6$ & $735.1 \pm 76.2$ & $4.45 \pm 0.09$ & 5 \\
$8-10$ & $185.9 \pm 31.5$ & $280.1 \pm 69.0$ & $4.55 \pm 0.05$ & 5 \\
69 & $120.6 \pm 11.9$ & $458.1 \pm 49.1$ & $4.74 \pm 0.06$ & 4
\end{tabular}

Initial tension, tension developed before capsaicin addition. Relative potentiation, maximal tension developed with capsaicin at concentrations of 60 $100 \mu \mathrm{M}$, as a percentage of the initial tension. responded to tyramine (up to $300 \mu \mathrm{M}$ ), but still showed a twitch response to field stimulation of about half the normal value $(68.4 \pm 8.3 \mathrm{mg}$ vs $126.6 \pm 22.6 \mathrm{mg}$, $n=5$ ). Under these conditions, Cap at concentrations of above $10 \mu \mathrm{M}$ dose-dependently augmented the twitch response, and the relative potentiation $(181.7 \pm 33.5 \%)$ was not significantly different from that observed in untreated preparations $(176.9 \pm 24.9 \%, n=5)$. Similarly, in the prostatic portion, the reserpine-resistant twitch response $(76.7 \pm 31.1 \mathrm{mg}$ in treated $v s 210.5 \pm 36.8 \mathrm{mg}$ in normal, $n=6$ ) was also enhanced by Cap (Figure 2).

6-Hydroxydopamine After treatment with 6-hydroxydopamine (6-OHDA), preparations of vas deferens did not contract in response to field stimulation or tyramine, and Cap did not restore the twitch response in either portion. Even when a small tetrodotoxin-resistant twitch response persisted after treatment with 6-OHDA (less than 5\%), Cap did not enhance the response.

Capsaicin In preparations from rats pretreated systemically with Cap, the response of the prostatic portion of the vas deferens to Cap was not substantially different from that of preparations from untreated rats (Figure 2).

Other inhibitors Prazosin $(0.3 \mu \mathrm{M})$ attenuated the twitch response of the epididymal portion by $36.0 \pm 6.9 \%(n=6)$ and that of the prostatic portion 


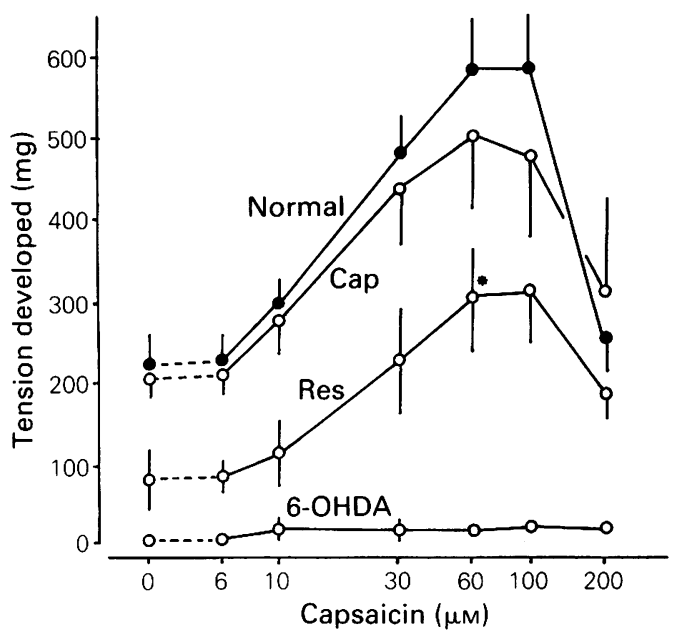

Figure 2 Potentiating effect of capsaicin on the prostatic portion of the vas deferens of rats chronically pretreated with reserpine, 6-hydroxydopamine and capsaicin. The ordinate scale shows the twitch tension developed in $\mathrm{mg}$. Normal untreated; Cap, capsaicin treated; Res, reserpine treated; 6-OHDA, 6-hydroxydopamine treated. Values are means \pm s.e.mean for preparations from 4 to 6 rats; s.e.mean shown by vertical lines. ${ }^{*} P<0.05$, compared with the value for the untreated preparation (unpaired $t$ test).

by less than $5 \%$. The prazosin-resistant twitch contractions were augmented by Cap (Figure 3).

The potentiating effect of Cap was not influenced by treatment of the preparation with yohimbine $(0.1-$ $3 \mu \mathrm{M})$, atropine $(0.1 \mu \mathrm{M})$, cimetidine $(10-100 \mu \mathrm{M})$, chlorpheniramine $(0.1 \mu \mathrm{M})$, indomethacin $(10-100 \mu \mathrm{M}$ for $60 \mathrm{~min}$, washed off), quinacrine $(10 \mu \mathrm{M})$, nordihydroguaiaretic acid $(10 \mu \mathrm{M})$, methylene blue $(10 \mu \mathrm{M})$, cocaine $(10 \mu \mathrm{M})$, desipramine $(3 \mu \mathrm{M})$ or ketanserin $(0.3 \mu \mathrm{M})$.

\section{Effect of capsaicin on contractions induced by a train of pulses at $2 \mathrm{~Hz}$}

To a lesser degree, Cap also enhanced the contractions of both portions of the vas deferens induced by a train of pulses at $2 \mathrm{~Hz}$ (as shown in Figure 4). In both portions of the preparations, prazosin suppressed the later phase of the contractions, without affecting the first phase appreciably. In the vas deferens from reserpinized rats, the contractile response induced by the train of pulses showed similar profiles to that induced in the presence of prazosin. The prazosin- and reserpine-resistant components of the contractions, which seemed to be non-adrenergic, were enhanced by Cap.

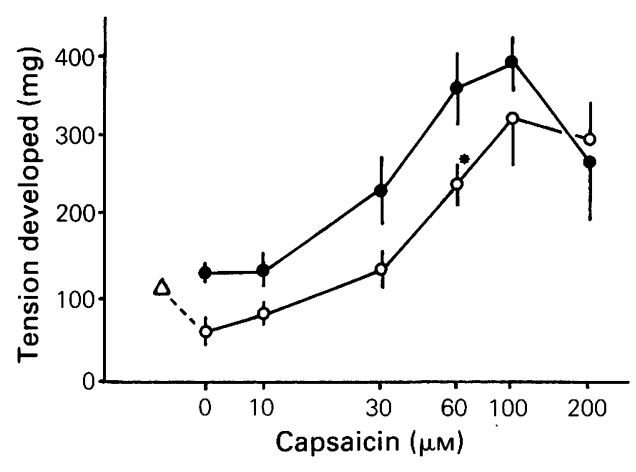

Figure 3 Effect of prazosin on the potentiation by capsaicin of the twitch response of the epididymal portion of rat vas deferens. The ordinate scale shows the twitch tension developed in $\mathrm{mg}$ in response to field stimulation at $0.1 \mathrm{~Hz}$. $(\Delta)$ indicates the tension developed before addition of prazosin. Prazosin $(0.3 \mu \mathrm{M}, 0)$ was added 20 min before capsaicin; (O) control. Each curve was obtained from paired preparations. Values are means for preparations from 6 rats; s.e.mean shown by vertical lines. ${ }^{*} P<0.05$, compared with the value for untreated preparations (paired $t$ test).

\section{Effects of peptides}

Like Cap, SP and substance K (SK) enhanced the twitch responses of both portions of the vas deferens without causing desensitization (Figure 5). SK was about 300 times more potent than SP in augmenting the response. However, SP and SK at concentrations sufficient to augment the twitch response also enhanced the NA-and ATP-induced contractions several fold (data not shown). Unlike Cap, rat calcitonin generelated peptide (CGRP) at concentrations of above $1 \mathrm{nM}$ inhibited the twitch response of both portions of the vas deferens (Figure 5).

\section{Discussion}

In this work we found that Cap enhanced the twitch response of rat vas deferens, irrespective of the age of rats, the region of vas deferens, and other experimental conditions, such as the calcium concentration, the pulse duration and the type of electrode. High concentrations of Cap had dual actions, initial potentiation followed by inhibition. The inhibition seemed to be a nonselective direct inhibitory effect, because high concentrations of Cap also abolished NA-induced contractions. The inability of various inhibitors to modify the potentiating effect of Cap indicated that Cap does not act through acetylcholine, histamine $\left(\mathrm{H}_{1}\right.$ and $\left.\mathrm{H}_{2}\right)$, 5-hydroxytryptamine $\left(5-\mathrm{HT}_{2}\right)$, prostaglan- 

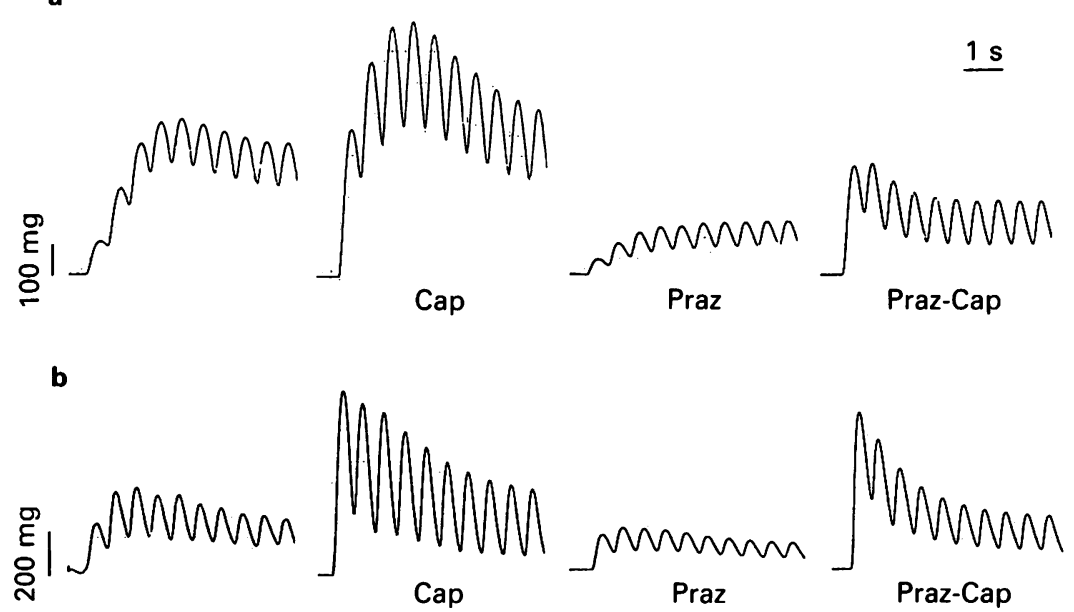

Figure 4 Typical records showing the potentiating effects of capsaicin on the contractions of the epididymal (a) and prostatic (b) portions of rat vas deferens stimulated with a train of pulses at $2 \mathrm{~Hz}$. The initial prazosin-resistant components of the contractions were enhanced by capsaicin. Stimulations were applied in the absence and presence of the agents indicated. Cap, $30 \mu \mathrm{M}$ capsaicin was added $10 \mathrm{~min}$ before stimulation; Praz, $0.3 \mu \mathrm{M}$ prazosin was added $20 \mathrm{~min}$ before stimulation; Praz-Cap, $0.3 \mu \mathrm{M}$ prazosin was added $20 \mathrm{~min}$ before capsaicin, and the stimulation was applied $20 \mathrm{~min}$ after prazosin.

dins, phospholipase $A_{2}$ or cyclic GMP, or by inhibiting NA uptake.

Cap was effective only when the vas deferens was stimulated: by itself it did not induce contractions or

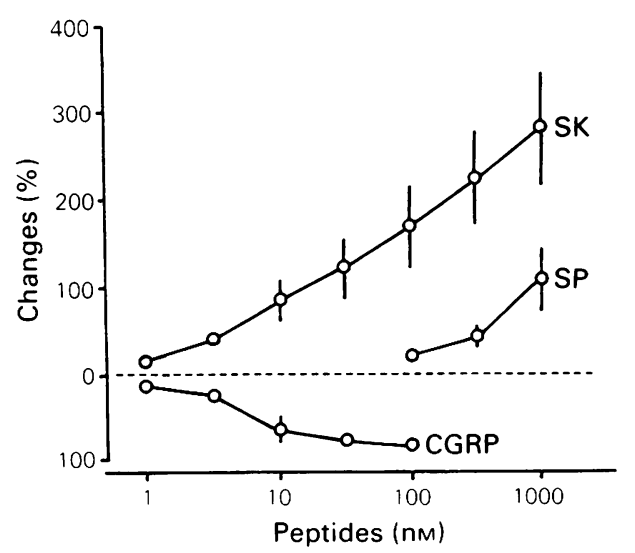

Figure 5 Effects of peptides on the twitch response of the prostatic portion of rat vas deferens induced by field stimulation at $0.1 \mathrm{~Hz}$. The ordinate scale indicates changes in twitch response expressed as percentages of the intial twitch height. SP, substance P; SK, substance $K$; CGRP, rat calcitonin gene-related peptide. Values are means for 5 preparations with s.e.mean shown by vertical lines. enhance the postjunctional contractile effects of NA and ATP. Thus it acts on some nerve ending to enhance the stimulation-evoked release of a transmitter or a co-transmitter.

Transmitter release by Cap has been reported: the contractile response of guinea-pig ileum induced by Cap is mediated by release of SP, which in turn stimulates cholinergic nerves (Chahl, 1982; Barthó et al., 1982; Rózsa et al., 1984). Facilitation of neuromuscular transmission by Cap has been explained as due to release of acetylcholine (Ganguly et al., 1987). Thus, it is conceivable that in rat vas deferens, Cap enhances release of an excitatory transmitter or a co-transmitter.

To determine whether Cap enhances the twitch response by increasing evoked release of NA, we examined its effect on preparations from rats treated with reserpine. In the reserpinized preparations, the twitch response induced by field stimulation tended to become irregular and was reduced in height (40$60 \%$ ). Nevertheless, Cap enhanced the twitch response (Figure 2) and the relative potentiation was not significantly different from that observed in an untreated preparation. In contrast, chemical sympathectomy by 6-OHDA completely abolished the twitch response, and even when a small response remained after this treatment, it was not potentiated by Cap. These results suggest that NA release or released NA itself does not contribute to the potentiating effect of Cap, but that Cap acts at least through sympathetic 
nerves. Further evidence for this idea was that prazosin-resistant components of the twitch contractions were enhanced by Cap and that the contractile action of the indirectly acting amine tyramine was not augmented, but attenuated, by Cap. These findings indicate that Cap augmented the non-adrenergic components of the twitch response mediated by sympathetic nerves, and that it is probably acted directly or indirectly through release of co-transmitter or other mediator that was released concomitantly with NA.

ATP has been reported to be the most likely candidate for the co-transmitter in rat vas deferens (French \& Scott, 1983; Sneddon et al., 1984). But Cap is unlikely to enhance the effect of ATP, because it attenuated the contractile action of ATP. Thus, some substance(s) other than ATP seems to contribute to the potentiating action of Cap.

SP is thought to mediate the contractile actions of Cap on several smooth muscle preparations, such as guinea-pig ileum (Barthó et al., 1982; Chahl, 1982), taenia coli (Szolcsányi \& Barthó, 1979) and trachea (Szolcsányi \& Barthó, 1982), and rat urinary bladder (Maggi et al., 1985). SK has been supposed to co-exist with SP in primary sensory neurones (Lundberg et al., 1985) and it mimicked the effect of Cap in inducing bronchoconstriction and fall in blood pressure (Lundberg et al., 1985). Thus several peptides with potent actions, such as SP and SK, mimic the complex peripheral effects of Cap. These findings suggest that in rat vas deferens, the effect of Cap might be due to an action in stimulating peptidergic nerves to release SP or SK. To examine this possibility, we compared the effects of Cap, SK and SP on the twitch response of rat vas deferens. We confirmed the previous observation (Nawa et al., 1984) that SK and SP mimicked the long lasting potentiating effect of Cap, SK being about 300 times more potent than SP. However, the effect of these peptides differed somewhat from that of Cap. If Cap releases SK or SP, then it should enhance the effects of NA and ATP, as SP and SK did. But in fact it inhibited the actions of NA and ATP. Moreover, SP and SK at high concentrations caused small, transient contractions of the preparations, the effect of SK on the epididymal portion being especially marked. Thus their actions seemed to differ from that of Cap. Furthermore, since neither SK and SP nor Cap produced tachyphylaxis in rat vas deferens, the existence of potent cross desensitization between Cap and SK or SP could not be detected. So it was impossible to determine definitely whether SP or SK was involved in the action of Cap.

At high doses, Cap has been shown to induce selective degradation of chemosensitive primary afferent neurones (Jancsó et al., 1977) containing neurokinin, such as SP (Jessell et al., 1978). Moreover, chronic treatment with Cap was found to abolish its in vitro effect on guinea-pig atria (Lundberg et al., 1984; Saito et al., 1986), and its dilator effect on the dog mesenteric artery (Rósza et al., 1984) and cat cerebral artery (Duckles \& Buck, 1982), and rat urinary bladder (Santicioli et al., 1986). Therefore, chronic treatment of rats with Cap, which possibly depleted the vas deferens of SP, was assumed to desensitize the preparations to the in vitro effect of Cap. However, in the present experiments, systemic pretreatment of rats with Cap did not abolish or attenuate the response of the vas deferens to Cap. Since Cap-resistant SPneurones have been found in the gastrointestinal tract (Holzer et al., 1980), SP in rat vas deferens may also not be depleted by treatment with Cap. Thus the action of Cap is unlikely to be mediated through SP or SK. Possibly some other peptide may contribute to its effect. One other peptide to be considered is CGRP.

SP- and CGRP-like immunoreactivities are reported to coexist or overlap in Cap-sensitive primary sensory neurones supplying vessels (Lundberg et al., 1985; Hanko et al., 1986; Saito \& Goto, 1986), the heart (Lundberg et al., 1985; Saito et al., 1986) and bronchial smooth muscle (Lundberg et al., 1985). Moreover, CGRP mimics the Cap-induced responses in rat duodenum (Maggi et al., 1986b) and guinea-pig atria (Lundberg et al., 1984; Saito et al., 1986). Thus CGRP might be involved in the potentiating action of Cap on the rat vas deferens twitch response. However, CGRP inhibited the twitch response, and so is unlikely to be responsible for the potentiating action of Cap.

From the present results and above considerations, we speculate that Cap enhances a stimulationinduced, prazosin- and reserpine-resistant non-adrenergic twitch response of rat vas deferens through some prejunctional mechanism. This mechanism is as yet unknown, but may be mediated by some peptide released in response to Cap from sensory neurones, which in turn acts on sympathetic nerves and increases stimulation-evoked release of a mediator or a cotransmitter responsible for the non-adrenergic twitch response. However, a direct action of Cap on sympathetic nerves cannot be ruled out.

We are grateful to Dr J.M. Van Nueten, Janssen Pharmceutica, Beerse, Belgium, for a gift of ketanserin, to Smith Kline \& French Laboratories, Philadelphia, PA, U.S.A. for supplying cimetidine, and to Taito-Pfeizer, Tokyo, Japan, for supplying prazosin. 


\section{References}

ANDO, K., KITAGAWA, K., KIYAMA, S., KAWAMOTO, T. AKITA, T., YAMAMOTO, I. \& TORIZUKA, K. (1987). Synthesis of a 37-residue peptide amide corresponding to the entire amino acid sequence of $\alpha$-form of rat calcitonin gene-releated peptide ( $\alpha$-rCGRP). Chem. Pharmac. Bull., $35,60-71$.

BARTHÓ, L., HOLZER, P., LEMBECK, F. \& SZOLCSÁNYI, J. (1982). Evidence that the contractile response of the guinea-pig ileum to capsaicin is due to release of substance P. J. Physiol., 332, 157-167.

CHAHL, L. (1982). Evidence that the contractile response of the guinea-pig ileum to capsaicin is due to substance $\mathbf{P}$ release. Naunyn-Schmiedebergs Arch. Pharmac., 319, 212-215.

DUKLES, S.P. \& BUCK, S.H. (1982). Substance P in the cerebral vasculature: depletion by capsaicin suggests a sensory role. Brain Res., 245, 171-174.

FRENCH, A.M. \& SCOTT, N.C. (1983). Evidence to support the hypothesis that ATP is a co-transmitter in rat vas deferens. Experientia, 39, 264-266.

GAMSE, R., MOLNAR, A.\& LEMBECK, F. (1979). Substance P release from spinal cord slices by capsaicin. Life Sci., 25, 629-636.

GANGULY, D.K., DAS, M., DAS GUPTA, A.K. \& CHAUHAN, S.P.S. (1987). Possible functional role of substance $P$ on the mammalian motor nerve terminals. Life Sci., 40, 289292.

HANKO, J., HARDEBO, J.E., KÅHRSTRÖM, J., OWMAN, C. \& SUNDLER, F. (1986). Existence and coexistence of calcitonin gene-related peptide (CGRP) and substance $P$ in cerebrovascular nerves and trigeminal ganglion cells. Acta physiol. scand. suppl., 127, 29-32.

HOLZER, P., GAMSE, R. \& LEMBECK, F. (1980). Distribution of substance $P$ in the rat gastointestinal tract. - lack of effect of capsaicin pretreatment. Eur. J. Pharmac., 61, 303-307.

HUA, X-Y.\& LUNDBERG, J.M. (1986). Dual capsaicin effects on ureteric motility: Low dose inhibition mediated by calcitonin gene-related peptide and high dose stimulation by tachykinins? Acta physiol. scand., 128, 453-465.

JANCSÓ, G., KIRARY, E. \& JANCSÓ-GÁBOR, A. (1977). Pharmacologically induced selective degeneration of chemosensitive primary sensory neurones. Nature, $\mathbf{2 7 0}$, 714-743.

JESSELL, T.M., IVERSEN, L.L. \& CUELLO, A.C. (1978). Capsaicin-induced depletion of substance $P$ from primary sensory neurones. Brain Res., 152, 183-188.

LUNDBERG, J.M., HUA, X-Y. \& FREDHOLM, B.B. (1984). Capsaicin-induced stimulation of the guinea-pig atrium. Involvement of a novel sensory transmitter of a direct action on myocytes? Naunyn-Schmiedebergs Arch. Pharmac., 325, 176-182

LUNDBERG, J.M., FRANCO-CERECEDA, A., HUA, X-Y., HÖKFELT, T. \& FISCHER, J.A. (1985). Co-existence of substance $\mathbf{P}$ and calcitonin gene-related peptide-like immunoreactivities in sensory nerves in relation to cardiovascular and bronchoconstrictor effects of capsaicin. Eur. J. Pharmac., 108, 315-319.
MAGGI, C.A., SANTICIOLI, P. \& MELI, A. (1985). Evidence for the involvement of endogenous substance $P$ in the motor effects of capsaicin on the rat urinary bladder. J. Pharm. Pharmac., 37, 203-204.

MAGGI, C.A., SANTICIOLI, P., MANZINI, S. \& MELI, A. (1986a). Capsaicin activates neurogenic non-adrenergic non-cholinergic relaxations of the isolated rat duodenum. Eur. J. Pharmac., 120, 367-370.

MAGGI, C.A., MANZINI, S., GIULIANI, S., SANTICIOLI, P. \& MELI, A. (1986b). Extrinsic origin of the capsaicin-sensitive innervation of rat duodenum: possible involvement of calcitonin gene-related peptide (CGRP) in the capsaicin-induced activation of intramural non-adrenergic non-cholinergic neurons. Naunyn-Schmiedebergs Arch. Pharmac., 334, 172-180.

MAGGI, C.A., SANTICIOLI, P., GIULIANI, S., ABELLI, L. \& MELI, A. (1986c). The motor effect of the capsaicinsensitive inhibitory innervation of the rat ureter. Eur. $J$. Pharmac., 126, 333-336.

NAWA, H., DOTEUCHI, M., IGANO, K., INOUYE, K. \& NAKANISHI, S. (1984). Substance K: A novel mammalian tachykinin that differs from substance $P$ in its pharmacological profile. Life Sci., 34, 1153-1160.

RÓZSA, Z., JANCSÓ, G. \& VARRÓ, V. (1984). Possible involvement of capsaicin-sensitive sensory nerves in the regulation of intestinal blood flow in the dog. NaunynSchmiedebergs Arch. Pharmac., 326, 352-356.

RÓZSA, Z., VARRÓ, A. \& JANCSÓ, G. (1985). Use of immunoblockade to study the involvement of peptidergic afferent nerves in the intestinal vasodilatory response to capsaicin in the dog. Eur. J. Pharmac., 115, 59-64.

SAITO, A. \& GOTO, K. (1986). Depletion of calcitonin generelated peptide (CGRP) by capsaicin in cerebral arteries. J. Pharmacobio-Dyn., 9, 613-619.

SAITO, A., KIMURA, S. \& GOTO, K. (1986). Calcitonin generelated peptide as potential neurotransmitter in guineapig right atrium. Am. J. Physiol., 19, H693-698.

SANTICIOLI, P., MAGGI, C.A. \& MELI, A. (1986). Functional evidence for the existence of a capsaicin-sensitive innervation of the rat urinary bladder. J. Pharm. Pharmac., 38, 446-451.

SNEDDON, P., WESTFALL, D.P., COLBY, J. \& FEDAN, J.S. (1984). A pharmacological investigation of the biphasic nature of the contractile response of rabbit and rat vas deferens to field stimulation. Life Sci., 35, 1903-1912.

SZOLCSÁNYI, J. \& BARTHÓ, L. (1979). Capsaicin-sensitive innvervation of the guinea-pig taenia caeci. Naunyn-Schmiedebergs Arch. Pharmac., 309, 77-82.

SZOLCSÁNYI, J. \& BARTHÓ, L. (1982). Capsaicin-sensitive non-cholinergic excitatory innvervation of the guinea-pig tracheobronchial smooth muscle. Neurosci. Letters, 34, 247-251.

WAHLESTEDT, C., BYNKE, G. \& HÅKANSON, R. (1985). Pupillary constriction by bradykinin and capsaicin: mode of action. Eur. J. Pharmac., 106, 577-583.

(Received May 27, 1987. Accepted June 9, 1987.) 